\title{
Characteristics of Public Participation in EA: the Potential to Improve Sustainable Environmental Management in China
}

\author{
Jing Du \\ Key Laboratory of Industrial Ecology and Environmental Engineering, MOE \\ Dalian University of Technology, No.2 Linggong Street Ganjingzi District, Dalian 116024, China \\ Tel: 86-411-8470-6172 E-mail: dujingdl@mail.dlut.edu.cn \\ Fenglin Yang (Corresponding author) \\ Key Laboratory of Industrial Ecology and Environmental Engineering, MOE \\ Dalian University of Technology, No.2 Linggong Street, Ganjingzi District, Dalian 116024, China \\ Tel: 86-411-8470-6328_E-mail: yangfl@dlut.edu.cn \\ Ling Xu (Corresponding author) \\ Key Laboratory of Industrial Ecology and Environmental Engineering, MOE \\ Dalian University of Technology \\ No.2 Linggong Street, Ganjingzi District, Dalian 116024, China \\ Tel: 86-411-8470-84706-069-602 E-mail: ashongdian@hotmail.com \\ Sachihiko Harashina \\ Department of Environment Science and Technology, Tokyo Institute of Technology \\ G5-9 4259 Nagatuta, Midori-word, Yokohama 226-0852, JAPAN \\ Tel: 81-45-924-5550Ｅmail: sahara@depe.titech.ac.jp \\ Binghua Li \\ Department of Asset Management and Urban planning, Leader University, Tainan, Taiwan \\ E-mail: biyulee@hotmail.com
}

The research is financed by National Natural Science Foundation of China (No.40801228)

\begin{abstract}
Public participation as one of the key concepts underpinning the principles and practice of good governance has been attached more and more importance by Chinese government, however, the current situation suggesting that it is not yet ripe for full public participation in China. This study reviews the origin and current situation of public participation in China, and based on reviews and interviews carried out in 2009 it argues that the legislative provisions for public participation are still confined to high-sounding principles. It goes on to argue that its weak enforcement in China lies not only in the undefined procedure of public participation according to the regulations, but also in the degree of information disclosure and a lack of active consultation, amongst other reasons. With reference to experience of public participation in neighboring Japan, some recommendations to improve the weaknesses are proposed.
\end{abstract}

Keywords: Public participation, Environmental Assessment, Characteristic, China

\section{Introduction}

Environmental assessment (EA) as a tool for mitigating impacts to the human environment has been recognized and identified internationally (Connelly and Smith, 1999; Lawrence, 1997; Noble, 2002; Sadler and Verheem, 1996; Wang et al., 2003). Considerable experience shows the potential of EA processes to evaluate the environmental implications of proposed project, policies, plans and programs (PPPs) and their alternatives in decision-making processes (Ahmed et al., 2005; Bina, 2008; Fisher, 2002; Gibson, 2000; Noble and Storey, 2001; Partidario, 2002). Alongside the growth of EA, the need to enhance public participation and its integration in the EA process has received a great deal attention in recent years (Cooper and Elliott, 2000; Del Furia and Wallace-Jones, 2000; Doelle and Sinclair, 2006; Kapoor, 2001; Morrison-Saunders and Early, 2008). The efficacy of alternative mechanisms in achieving this goal have been central themes in the literatures, because of the benefits of public participation (Cooper and Elliott, 2000; Doelle and Sinclair, 2006; Hartley and Wood, 2005; Vanclay, 2003). While the benefits of public participation are assumed to be obvious and substantial generally by most scholars and practitioners, O'Fiarcheallaigh (2009) classifies the purposes of public participation in EA and indicates how to pursue it effectively. The implementation of public participation has been included in EA legislations in many countries, which has been due to two factors-agency requirements that increasingly create a legal mandate for public participation and the growing sense that, regardless of legal mandate, traditional decision-making modes often fail to lead to credible and efficacious management decisions (Poisner, 1996; Halvorsen, 2001).

China now experiences its economic growth with significant environmental degradation. EA was adopted with 
the aim of balancing the pursuit of economic, social and environmental objects and moving towards greater environmental sustainability. Increasingly evident shortcomings about public participation being absent from EA process led scholars and practitioners to seek approaches and instruments, eventually resulting in that public participation became a required component in EA process in Environmental Impact Law of the People's Republic of China (EIA Law) approved by the National People's Congress in 2003. It is stated in the law that the State encourages relevant work units, experts and the public to participate in environmental impact assessments in appropriate ways and the opinions of those related work units, experts and the general public should be consulted before the approval of development plans and projects. The public have experienced unprecedented change with respect to their legal right to participate in decisions affecting the environment since public participation and relative issues were stipulated in a set of draft measures and regulations after the enactment of the EIA Law. However, the record to date has fallen short of expectations. Some measures and regulations are too vague and general and it is not easy to achieve the right of the public to participate. In China, although the public participation in EA process do shift the locus of decision making in Xiamen PX (Paraxylene) Event case, most cases indicate that public participation is almost just for obtaining public input into decisions.

To make clear the characteristics of public participation in the EA process in China, in addition to recent literature on the subject, six semi-structured interviews with thirteen interviewees were conducted in February and March, 2009. Three were held with two bureaucrats from a center which is affiliated with Ministry of Environmental Protection of China, and five representatives from consultancies who have vast experience in organizing participation of the public. Two interviews were carried out with five academics from two top universities who have been actively involved in studies of public participation and relative fields. And one was held with an officer of environmental non-government organization (NGO) devoted to popularize public knowledge about environmental law, to raise public legal consciousness, and to offer pollution victims legal assistance to safeguard their environmental rights and interests. In the interviews, interviewees' personal experience of implementation of public participation in EA process, their personal observation about hurdles in public participation practices in China and their interpretations of the reason of its weak enforcement were focused on.

Based on the literature review and data got from interviews, this paper examines the evolution of environmental assessment and public participation in EA process in China and, in particular, explores the reason why the effectiveness of implementation often remains a challenge. Some recommendations are proposed with reference to experience of public participation in neighboring Japan and then we conclude by summarizing and discussing our findings.

\section{Development of environmental assessment and public participation in China}

EA as an attempt to improve the quality of human life in a lasting way by examining and documenting the potential environmental impacts of a proposed activity has been introduced in China since 1979 when the Environmental Protection Law of PRC (for trial implementation) was enacted. Although the trial implementation law did not stipulate the EIA procedures in details, it nonetheless set a milestone leading to the gradual implementation of environmental assessment in China (Tang et al., 2008). And simultaneously, the concept of public participation which referred as 'All working units and individuals had the rights to report and to take prosecution actions when pollution was observed' had also been reflected in it. In 1981, Guidelines of Environmental Management for Construction Projects were issued for the implementation of EIA and were amended in 1986. The revised vision covered more specific requirements in terms of projects, EIA preparation and review procedures, EIA approval authority and responsible parties, the detailed requirements about EIA reports and EIA practitioner's qualification and certification system ( $\mathrm{Gu}$ and Sheate, 2005). In 1998, the guidelines were amended again and issued as Ordinance of Environmental Management for the Construction Projects. This Ordinance was the update of 1986 regulations and three different EIA reports (Environmental Impact Statement, EIA form, EIA registration form) were required, respectively, with the likelihood that how significant impact to the environment the proposed project would cause. In 2003, China enacted its EIA Law in which a form of Strategic Environmental Assessment (SEA) for plans and programs (referred to here as PEIA) had also adopted, besides EIA. It expanded the EIA mandate to encompass government plans (government plans for land use and regional development, as well as plans for industry, agriculture, energy, transportation, urban development, tourism, and natural resource development must undergo PEIA), as well as construction projects.

Although EIA has existed in China since 1979, prior to 2003, the public participation had been absent from the process legally. Since the beginning of the 1990s, the Chinese authorities have increasingly recognized the potential of the public and were taking steps to promote public participation in environmental activities. In 1993, Notice on Strengthening the Management of EIA for Construction Projects Funded by International Financial Organizations was promulgated. And in this notice, public participation was stated as an important part of EIA and it was required that public participation should be included in the assessment of social issues to ensure the interests of affected parties and social group were reasonably considered and compensated. The public rights of participating in the decision-making process are also stipulated in some laws and regulations such as, China's Agenda 21, Action Plan on National Environmental Publicity and Education, Water Pollution Prevention Law, 
Symposium on Population, Natural Resources and Environment and so on until 2003. The year 2003 can be regarded as a watershed moment for both EIA and public participation evolution in China. The EIA Law was enacted in this year and this law built on the existing EIA framework in two significant ways. First, it adds PEIA overlay to the existing EIA process; second, which is more relative to our topic, the EIA law made public participation a required component of the process although it lacks defined scope, procedure and forms of organization. According to the law, the EIA procedure and public participation in EIA process in China has been summarized in the figure 1. Aiming at filling in the gap between the law and practice concerning public participation in EA process, in February 2006, China's State Environment Protection Administration (SEPA) officially issued Provisional Measures for Public Participation in Environment Impact Assessment (2006 Measures), which particularly points to public participation as an important means of solving environmental problems in China, and states that the process of providing environmental information is a requisite for public participation in environmental affairs. In May 2008, Measures for the Disclosure of Environmental Information (for trial implementation) (2008 measures) were put into effect. Besides the requirement on open government information, the measures made specific requirements on corporate disclosure and also stated that every March $31^{\text {st }}$, environmental authorities should publish an environmental information disclosure report to improve public access to environmental information.

\section{Weak enforcement of public participation in China}

\subsection{Undefined procedure of public participation}

EIA law places a requirement on the responsible entities (refer to proponents and consultancies, note 1) drafting an EIA Statement (EIS) to consider all opinions of the relevant departments, experts and the public, and to include their reasons for accepting or rejecting the opinions in the EIS submitted for approval and gives the option of holding a hearing or adopting other forms of soliciting public opinions. However, the text of EIA law makes only limited references to the scope of public participation in the EA process. The 2006 measures, article 8 states that within 7 days after the consultancy being confirmed, some initial information, that are, the basic information of responsible entities, procedure and primary content of EIA work, and major items and methods of public participation must be identified. Thereafter, once the responsible entity has finalized the draft EIS, it should notify the public of EIS information, methods and places for the general public to consult the abridged version of EIS, scope and major issues of concern related to soliciting public opinions and specific forms and time for soliciting public opinions prior to submitting it for approval.

Although these legislative steps have the potential to provide a good starting point for public participation, to date, the procedure which address the role of the public have been designed largely on the assumption that the public is expected to just indicate its level of interest or concern about the information of proposed action. The procedure is considered undefined and less than transparent basically because it doesn't impenetrate the whole EIA process, that is, lack of public participation for scoping and follow-up in EIA process (shown in figure 2). In the scoping process, consultancy gathers some data regarding the area of the proposed project, in addition to a project description and some basic data provided by proponent. This part should include an investigation of local attitudes towards the projects to make room for the public to participate in this process. Unfortunately, at this stage now, local people generally do not have detailed information about the project and the consultancies generally rely on the secondary data gathered through other offices. And after the final EIS approved, public should be given the opportunity to access relevant information especially the part of append explanations of what public opinions were accepted and which were not accepted in the final EIS as the feed-back process for public participation.

\subsection{Poor public access to environmental information}

The implementation of public participation in the EA process and even environmental field over recent years shows us that due to various limitations, conditions are not yet ripe for full public participation. Thus, Chinese central government starts to put emphasis upon environmental information disclosure as a precondition for public participation aiming at making public access to environmental information possible and promulgated 2008 measures. Environmental information in these measures refers to not only government environmental information but also enterprise environmental information. Government environmental information means information made or obtained by environmental protection departments in the course of exercising their environmental protection responsibilities and stored in a given form, while, enterprise environmental information means information recorded and stored by enterprises in a given form and relating to environmental impact arising from enterprise operational activities and enterprise environmental behavior.

Until now, Chinese central government has made great progress on environmental information disclosure. Nevertheless, many local government agencies and enterprises regard compiling and disseminating information as a nuisance, and they refuse to release environmental information even the information they are legally obliged to disseminate. The measures do provide a legal basis, but, some local government is still unwilling to act or looks for excuses to avoid acting. Because there is no requirement to deal with no compliance of local governments, it is hard to bring them to account (China dialogue, 2009). Enterprises tend to release information 
only to the extent necessary to requirements. One of the excuses is commercial confidentiality, and even worse, some enterprises use "manipulated data" practices to mask actual environmental performance so that some disclosed information may not be entirely accurate (information got from interviews). Manipulating the disseminating information behavior can result in misleading the public and if it was observed, enterprises will lose the trust of the public. Information disclosure is the fundamental basis for the public participating in the EA process. Lost the trust from the public, it is difficult for the governments and enterprises to solicit public opinions during their decision making processes. More detailed items relative to exemplary punishments should be stipulated in the measures to supply the current gap. And China should fully execute the enforcement functions of responsible departments, the supervisory functions of the public and the self-monitoring functions of enterprises.

\section{3 lack of active consultation}

The third reason of the limited progress of public participation in EA is lack of active public consultation. Public consultation can facilitate the exchange of information between the agency and its interest groups and to provide a shared understanding of issues under consideration. It supports open and accountable processes whereby individuals and groups can contribute to decision-making and influence outcomes. In 2006 measures, it is required that after relevant information is disclosed, the public may put forward suggestions and opinions related to EA process or EIS to responsible entities or departments in charge of environmental protection that are approving EIS. On the surface, this may seem to be a constructive approach, aiming at soliciting public opinions and comments. The public is expected to make substantive comments on the proposal, not just indicate its level of interest or concern. In practice, however, quite the opposite has occurred that the public comments are too brief or inconspicuous within a short period of notice such that it severely diminishes the effect of public consultation. Such requirement is unrealistic underlined by the assumption that if an opportunity is provided to the public, it will be ready, willing and able to step up and make constructive comments, and those comments will be incorporated into decision-making process.

According to 2006 measures, responsible entity should, in accordance with the principles of openness, equality, broadness and representativeness, take into consideration such factors as profession, region, expertise, expressiveness and intensity of environmental impact, and reasonably select the units and individuals as representatives from whom to solicit opinions. In many cases, large groups of citizens are not knowledgeable about EIA, its role in decision making, the accessibility of EIS documents, or their right to comment on them. Issues raised by individual citizens often are related to their personal local situation, have no scientific legitimacy, and are often considered inadequate and, therefore, ignored by EIA professionals. Consequently, Advisory groups such as environmental NGOs representing interest groups can make sense in this point.

\section{Recommendations}

After a few years of development, with special emphasis on the recent years, China's public participation legislation has formed a strong base and is now actively developing effective implementation methods. Over this period, it has become apparent that public participation is still problematic and many issues remain unresolved and require urgent attention. As Japan is one of the world leaders in protecting the environment especially experiences in the enforcement of public participation, some recommendations for strengthening and improving China's public participation system are proposed with reference to the experience in neighboring Japan.

\subsection{Add procedure in scoping and follow-up processes to make an information loop in the reforming legislation}

Expert opinions of environmental values and impacts-including those of EIA practitioners-can differ from the way citizens feel about the state of their living environment and how intended activities may impact on the various characteristics of that environment. Therefore, information about citizen's judgments about the qualities of their living environment might provide useful input for EIA. In Japan, during the scoping process, the project proponent is obliged to provide a forum which enables people to have information about the project. The forum proposed for this is public displays and public meetings. With public displays, the project proponent provides visual displays illustrating where, when and how the proposed project will be built. Such project visualization describes clearly the purpose of the project, its location, and activities at the pre-construction, construction and operational stages. Local people and other interested parties visit the displays and learn about the project. These public displays are then followed up by public meetings. In these meetings people could voice their opinions, and raise concerns, complaints and questions related to project. Their input will be more directed because they have learned about the project through public displays. When the draft EIS is submitted for approval, the reason of whether the public comments are adopted or not should be explained and included in the documents usually as the consultation reports. Then, the draft EIS, final EIS and consultation reports are open to the public to let them know the results of comments. And if anyone feels the explanation is not clear, he can send comments directly to the environmental agency in charge of this problem. This process realizes information feedback and makes a real information loop in public participation.

Similar to Japan, the 2006 measures ideally required the content of explanation of whether the comments are adopted and encouraged the public to make follow-up comments by considering unclear explanation. But in 
practice, the documents are usually not open to the public, that is, feedback process is absent in both legal items and practice. Without feedback, how the public know the results of their comments and decide whether a follow-up comment is necessary and how can the responsible entities make sure whether the explanation satisfy the public. That is to say, without feedback process, the public participation can be seen defective. Thus, it is urgent to add public participation procedure in scoping and follow-up processes to make an information loop in the reforming legislation in China.

\subsection{Improve the administration of NGOs}

Environmental NGOs, address a gap in the relationship between people and government, and start from the principle of benefiting the Earth. The legal status of NGOs has been insured since the NGO law in Japan was enforced from December 1998. Then, environmental NGOs promote citizens activities on incidents of environmental pollutions and are dramatically able to influence government policy creation, especially in environmental protection or social welfare in recent years.

NGOs are playing an increasingly important role in mobilizing the Chinese citizens around environmental issues. However, the power and the influence of the NGO sector have been very limited compared to Japan in terms of relative large membership and robust funding, as well as their influential power. Now, in China, most environmental NGOs are considered to be government-organized NGOs, which are established by state agencies or by well-known Chinese leaders, while individual-organized and volunteer-organized NGOs are limited. As the institutional system is different between China and Japan, it is hardly to say that the administrative methods of NGOs in Japan is appropriate for China, but it is suggested to improve the administrative activities of environmental NGOs according to Japanese experience. Such as, the government can provide groups with professional training and environmental education; support the NGOs activities in building platforms for communication; promote NGOs' transmitting action to public by providing environmental data to them; and ensure NGOs are adequately represented on both formal and informal deliberative bodies.

\subsection{Nurture civil awareness}

Public awareness and environmental education are paid much attention, when we consider the methods to solve environmental problems, which can directly contribute to improve our daily life. In Japan, the enactment of Basic Law for the Recycling-based Society employs a concept of "environmental culture" to promote public awareness of environmental protection and its moral value. A bill to raise public awareness and promote environmental education was passed in 2003 and it placed great stress on the necessity and importance of promoting capacity building.

In China, the public are usually weak in recognizing the harm of certain kinds of pollution behaviors occurring around them, and the lack of the ability to estimate whether an action is legitimate or not. Thus, environmental education which also can be extended as "capacity building" should be paid more attention to nurture civil awareness. The environmental education should be implemented not only in schools, companies, local communities, but also in governments. In China, the public have been used to relying on the government for decades, thus nurturing the public officials' consciousness that civil awareness is the ultimate force to promote the degree of civilization and forward the democracy and equality within this society can be an useful method to promote the public participation process. In addition, it is also important to nurture the civil awareness of their supervisory duties for government activities.

\section{Conclusion}

Early, active and meaningful participation particularly by the different levels of governments, and public segments most affected by the proposed projects and plans is a positive step towards effectively using the EA as a management tool for mitigating impacts to the human environment. Without adequate and meaningful public participation, the EA process lacks the necessary social component that makes it a truly effective sustainable development tool. Although Chinese central government made a great effort to improving the public participation in EA process and even decision-making process, the legislative provisions for public participation in the laws, regulations and other complementary legislation are still confined to high-sounding principles on the limited process and weak enforcement in China, due mainly to less than transparent procedure, weak information disclosure and lack of active consultation. Much work remains to be done in the areas of making laws and regulations more explicit and standardized, processing environmental information, administrating non-government organizations and improving capacity building process. The recommendations in this paper provide a good starting point for focusing this work.

\section{References}

Ahmed K, Mercier JR, \& Verheem R. (2005). Strategic environment assessment: concept and practice. Environment Strategy Note 14, World Bank, Washington DC.

Bina O. (2008). Context and Systems: Think More Broadly About Effectiveness in Strategic Environmental Assessment in China. Environmental Management, 42: 717-733.

Chinadialogue. (2009). One year of open information. [Online] Available: http://www.chinadialogue.net 
Connelly J, \& Smith G. (1999). Politics and the environment: from theory to practice. New York: Routledge.

Cooper L, \& Elliott J. (2000). Public participation and social acceptability in the Philippine EIA process. Journal of Environmental Assessment Policy and Management, 2(3):339-367.

Del Furia L, \& Wallace-Jones J. (2000). The effectiveness of provisions and quality of practices concerning public participation in EIA in Italy. Environmental Impact Assessment Review, 20:457-479.

Doelle B, \& Sinclair AJ. (2006). Time for a new approach to public participation in EA: Promoting cooperation and consensus for sustainability. Environmental Impact Assessment Review, 26:185-205.

Fisher TB. (2002). Strategic environmental assessment in transport and land use planning. London: Earthscan.

Gibson RB. (2000). Favoring the higher test: contributions to sustainability as the central criterion for reviews and decisions under the Canadian Environment Act. Journal Environmental Law Practice, 10:39-56

Gu LX, \& Sheate WR. (2005). Institutional challenges for EIA implementation in China: A case study of development versus environmental protection. Environmental Management, 36(1): 125-142.

Halvorsen KE. (2001). Assessing public participation techniques for comfort, convenience, satisfaction, and deliberation. Environmental Management, 28(2): 179-186.

Hartley N, \& Wood C. (2005). Public participation in environmental impact assessment-implementing the Aarhus Convention. Environmental Impact Assessment Review, 25:319-340.

Kapoor L. (2001). Towards participatory environmental management? Journal of Environmental Management, 63:269-279.

Lawrence D. (1997). Integrating sustainability and environmental impact assessment. Environmental Management, 21(1): 23-42.

Morrison-Saunders A, \&Early G. (2008). What is necessary to ensure natural justice in environmental impact assessment decision-making. Impact Assessment and Project Appraisal, 26(1):29-42.

Noble B, \& Storey K. (2001). Towards a structured approach to strategic environmental assessment. Journal of Environmental Assessment Policy and Management, 3(4): 483-508.

Noble BF. (2002). Strategic environmental assessment: what is it and what makes it strategic? Journal of Environmental Assessment Policy and Management, 2(2): 203-224.

O'Fiarcheallaigh C. (2010). Public participation and environmental impact assessment: Purposes, implications and lessons for public policy making. Environmental Impact Assessment Review, 30:19-27.

Partidario MR. (2002). Strategic environmental assessment: key elements and practices in European approaches. Course Manual. Training course presented at the $22^{\text {nd }}$ Annual Meeting of the International Association for Impact Assessment, Netherlands Congress Center, the Hargue, June 15-16.

Poisner J. (1996). A civic republican perspective on the National Environmental Policy Act's process for citizen participation. Environmental Law, 26: 53-94.

Sadler B, \& Verheem R. (1996). Strategic environmental assessment: status, challenges and future directions. Ministry of Housing, Spatial Planning and the Environment of the Netherland. Netherland: the Hague.

Tang B, Wong S, \& Lau MC. (2008). Social impact assessment and public participation in China: a case study of land requisition in Guangzhou. Environmental Impact Assessment Review, 28: 57-72

Vanclay F. (2003). International principles for social impact assessment. Impact Assessment and Project Appraisal, 21(1): 5-11

Wang Y, Morgan RK, \& Cashmore M. (2003). Environmental Impact Assessment of Projects in the People's Republic of China: New Law, Old Problems. Environmental Impact Assessment Review, 23: 543-579.

\section{Notes}

Note 1. Organizations accepting entrustment to provide technical services to construction project EIA, after going through verification of qualifications by the State Council Administrative Department in charge of environmental protection, and must be issued with qualification certificate in China. 


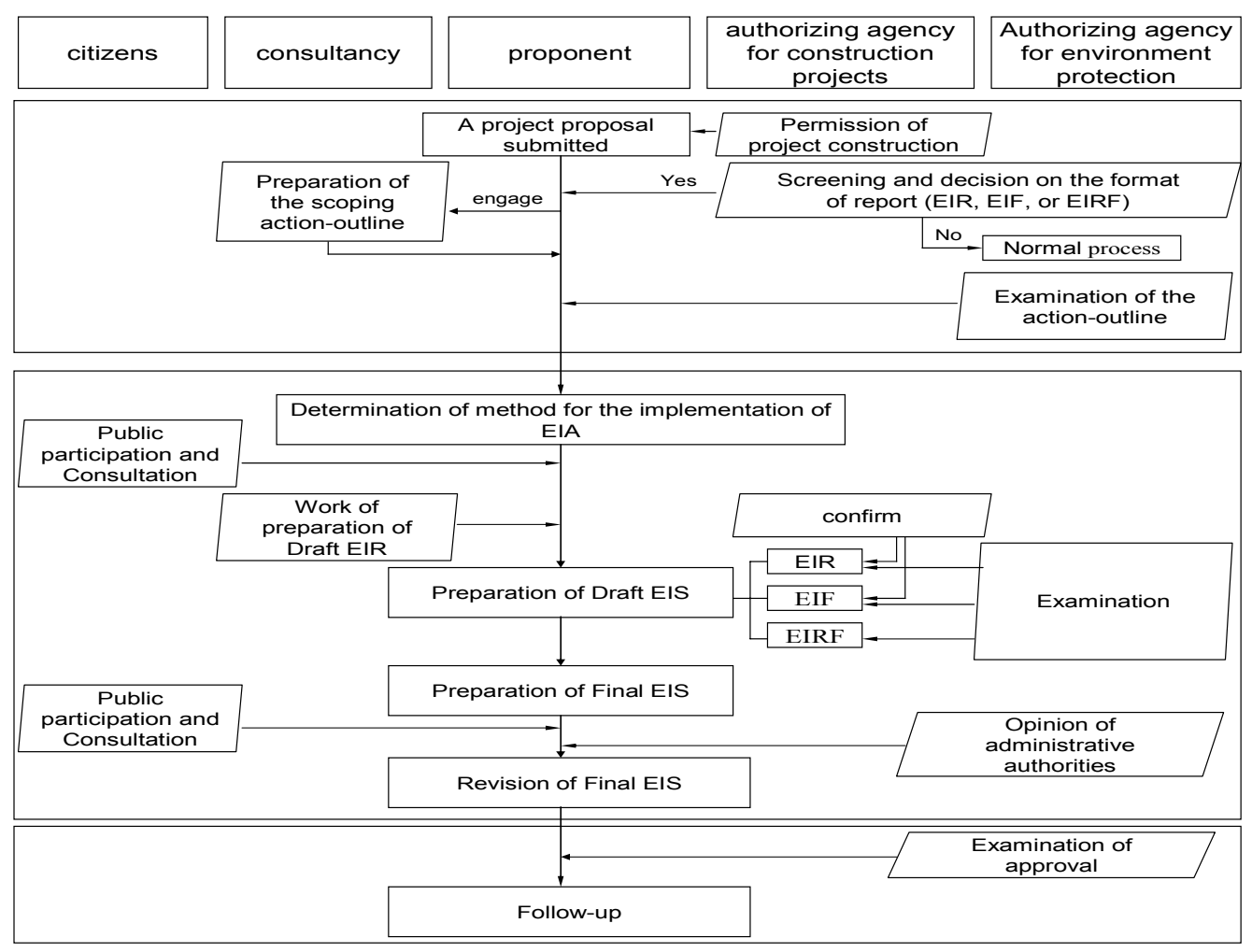

Figure 1. The EIA procedure and public participation in EIA process in China

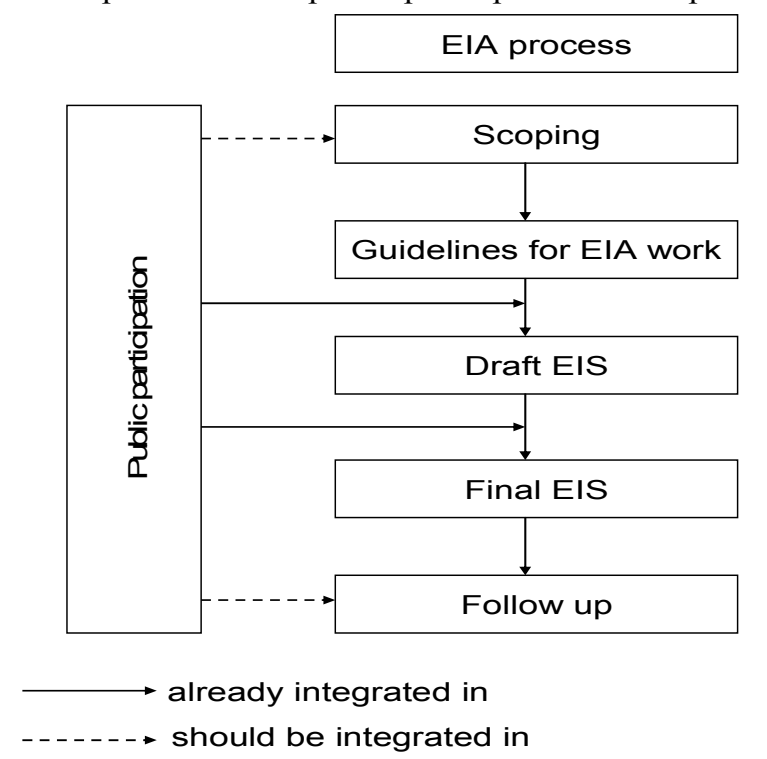

Figure 2. Integration of pubic participation in the EIA process 